\title{
Les revistes bilingües a la Tortosa de la II República
}

\author{
The bilingual magazines in Tortosa of the 2nd Republic
}

\author{
M. Carme Gombau Domingo \\ carmegombau@gmail.com \\ Universitat Jaume I
}

\begin{abstract}
Resumen: En l'àmbit de la premsa tortosina en català del primer terç del segle xx es donen dues actituds lingüístiques: la fabriana i la tortosinista. La primera, partidària del model de llengua de l'IEC, era minoritària als anys vint però es generalitza a partir dels anys trenta ( $\mathrm{La}$ Veu de Tortosa, La Veu Comarcal, Ara, Acció, Vida Tortosina i Lluita); mentre que el tortosinisme, que es correspon amb una ideologia cada cop més localista i que eleva el «parlar tortosí» a la categoria de llengua, queda reduit durant la II República a tres revistes bilingües: La Zuda, Germanori La Santa Cinta.
\end{abstract}

Palabras clave: premsa tortosina, actituds lingüístiques, tortosinisme, fabrisme

Abstract: There were two linguistic actitudes in the tortosine press of the first third in the 20th century: the fabriana amb the tortosinista. The fabriana, in favour of the IEC linguistic model, was in minority during the 20's, but it became widespread from the 30's (La Veu de Tortosa, La Veu Comarcal, Ara, Acció, Vida Tortosina i Lluita). The second, the tortosinista, had a local ideology and compared the tortosinisme talk as a complet language, but it was reduced during the II Republic to three magazines: La Zuda, Germanor i La Santa Cinta.

Keywords: tortosine press, linguistic actitudes, tortosinisme, fabrisme 
La premsa tortosina del segle xIx i de principis del xx és escrita exclusivament en castellà, siga de la ideologia que siga. Tanmateix, al desembre de 1899 sorgeix el primer setmanari escrit en català, La Veu de Tortosa, dirigit pel polifacètic Francesc Mestre i Noé fins que desapareix (desembre de 1902). El succeeix el setmanari/quinzenari La Veu de la Comarca (1903-1909), també conservador, dirigit pel controvertit Joan Abril Guañabens. I no és fins deu anys després que apareix en escena el Bolletí de la Lliga Espiritual de la Mare de Dén de la Cinta (1919-1921).

El Bolletí representa, a nivell lingüístic, l'adopció del codi ortogràfic fabrià a Tortosa, posició que es veu generalitzada entre els literats i els periodistes a partir dels anys 30. L'actitud que anomenem fabriana, és a dir, aquella que assumeix el model ortogràfic i morfosintàctic de l'IEC, s'inicia amb el Bolletí i s'estén progressivament durant la II República: des de les publicacions conservadores La Veu de Tortosa (1930-31), La Veu Comarcal (1934-35) i el diari Ara (1935-36), fins a la revista Vida Tortosina (1927-1936) i el quinzenari Acció (1933-34), totes dues representants d'un moderat catalanisme nacionalista d'esquerres, el d'Acció Catalana Republicana. Paral lelament es dóna una altra actitud lingüística entre els tortosins, que esdevé progressivament minoritària al tercer decenni: la tortosinista. Aquesta és manifesta a través de tres revistes bilingües, culturals i de caràcter apolític, únics espais on es permeté escriure en català durant la dictadura de Primo de Rivera i que sobrevisqueren durant la II República: La Zuda (1913-1933), d’un abast cultural i cronològic molt més ampli que les altres dues, Germanor (1918-1936) i La Santa Cinta (1928-1936).

La Zuda i Germanor poden ser considerades com a revistes de resistència pel que fa a la llengua davant la forta oposició que el català havia rebut des del Bisbat tortosí amb Pedro Rocamora i, a partir de 1925, amb el basc Félix Bilbao (cap dels dos bisbes no donà mai suport al catolicisme de tradició catalana). D'altra banda, aquell mateix any emergia com a alcalde de la ciutat un altre prohom de la Dictadura, Joaquín Bau Nolla, gens procliu a donar suport a la llengua. Aquest clima sociopolític de la ciutat explica que les aportacions en català a les publicacions esmentades foren cada cop més escasses i limitades als escrits dels tortosinistes, de manera gairebé exclusiva a Germanor i progressiva a La Zuda. L'inici del declivi de la Dictadura coincideix amb l'obertura de La Zuda a noves col laboracions d'homes que, a la vegada, foren els iniciadors de la revista Vida Tortosina, la qual esdevé portaveu d'Acció Catalana a partir de 1930 i passa a ser escrita exclusivament en català. D'altra banda, a partir de 1928 sorgeix una altra revista bilingüe, catòlica i tortosinista, arran de la commemoració del xv cinquantenari de la Baixada de la Verge de la Cinta a la ciutat: La Santa Cinta. Per tant, Germanor i La Santa Cinta, totes dues d'un tarannà ultracatòlic, juntament amb els col laboradors tortosinistes de $L a Z u d a^{1}$, constitueixen el veritable reducte del tortosinisme dels anys 30,

1 Els tortosinistes foren incapaços de definir el seu model lingüístic amb una normativa clara que poguessen aplicar els literats, periodistes i intel lectuals tortosins de l'època -retret que se'ls fa des de la revista Vida Tortosina-, tasca de la qual s'havia d'encarregar la frustrada Acadèmia tortosina. Aquesta havia de ser creada a Tortosa a semblança de la Societat Castellonenca de Cultura, i dedicar-se a l'estudi i depuració de la història i la llengua de Tortosa, amb la idea que es

SCRIPTA, Revista internacional de literatura i cultura medieval i moderna, núm. 7 / juny 2016 / pp. 80 - 101 ISSN: 2340-4841 · doi:10.7203/SCRIPTA.7.8443 
com a ideologia localista (no comarcana), d'un gran fervor a la Verge de la Cinta i a la ciutat de Tortosa i amb la bandera del «parlar tortosí», que eleven a la categoria de llengua. Vegem-ho.

\section{La zuda}

El Boletín del Orfeó Tortosí es publica per primer cop a la ciutat el 31 de març de 1913 i consta d'un total de 217 números, el darrer dels quals correspon al juliol de 1933 -segons el fons de l'Arxiu Històric Comarcal de les Terres de l'Ebre. Es tractava d'una revista cultural i literària mensual que sorgia com a mitjà d'expressió dels socis de l'Orfeó, escrita majoritàriament en castellà, i editada per la Impremta Querol de Tortosa. El president de l'entitat i director de la revista fou el metge Secundí Sabaté, mentre que Ramon Vergés Pauli n’era el fundador i s'encarregà de la «Secció Excursionista» del rotatiu.

A partir del mes de maig de 1914 (núm. 16) el rotatiu adopta el nom de La Zuda. Boletín del Orfeó Tortosí i l'any següent (núm. 33) es fa constar en la portada el subtítol Revista Cultural Ilustrada i el nom del nou director gerent de la revista, José Marqués Escardó. Un any després la societat decideix canviar-ne el nom perquè, com explica Josep Matamoros en «Visiones tortosinas» (núm. 42), l'entitat ja no disposava d'una massa coral que la identifiqués, i passa a anomenar-se Ateneo de Tortosa; conseqüentment, la revista s'anomena des d'aleshores La Zuda. Boletín del Ateneo de Tortosa. A partir d'aquest moment s'hi inicien diversos cicles de conferències de caire científic, artístic, moral i literari. Fins aleshores des de la tribuna de l'Orfeó s'havien realitzat «converses», és a dir, conferències que no tenien una periodicitat establerta i que versaven sobre temes diversos relacionats amb Tortosa i la cultura en general, sempre al marge de la política, i que sovint eren reproduïdes a La Zuda, com, per exemple, la que realitzà Marcel lí Domingo el 5 de desembre de 1913 sobre la supressió dels «consums» a la ciutat. El primer cicle de conferències fou inaugurat pel director de l'Observatori de l'Ebre, el P. Cirera (núm. 12). Posteriorment, la societat amplia els seus objectius culturals; per exemple, s'hi imparteixen classes de solfeig, dibuix, comptabilitat, francés i anglés per als fills dels socis, i disposa d'una biblioteca amb 626 volums. D’altra banda, es diversifica en noves seccions, a més de l'Excursionista i de la d'Sports. Així, pel gener de 1917 es constitueix la Secció Recreativa (núm. 47), encarregada d'organitzar vetllades literàries i teatrals i altres festes.

Tot i l'escassesa de textos en català durant els primers anys de La Zuda, cal remarcar l'aportació de

netegés el tortosí de barbarismes i que en fixés les regles precises. Per això, al voltant dels anys 30 els tortosinistes queden relegats a un grup menor d'intel lectuals lligats a una ideologia conservadora, molt catòlica i molt localista. Cal dir que, gràcies a les anàlisis lingüístiques realitzades sobre el Bolletí i les tres revistes bilingües i, en especial, la recapitulació comparativa dutes a terme en la tesi de doctorat La premsa tortosina en català del primer tery del segle XX (Gombau 2015), es pot fer una idea molt aproximada del model de llengua emprat pel tortosinisme. Aprofite aquesta nota per donar les gràcies a Tomàs Martínez Romero i a Lluís Gimeno Betí pel seu suport en aquesta recerca.

SCRIPTA, Revista internacional de literatura i cultura medieval $i$ moderna, núm. 7 / juny 2016 / pp. 80 - 101 ISSN: 2340-4841 · doi:10.7203/SCRIPTA.7.8443 
Ramon Vergés Pauli amb textos extrets d'Espurnes de la llar, entre altres. També són interessants les aportacions de Francesc Lleixà -pintor i poeta tortosí que vivia a Barcelona i col laborador també de La Veu de la Comarca- el qual hi inicia una secció amb el títol «Notes de ma cartera». D’altra banda, cal destacar la col laboració d'historiadors catalans com Francesc Carreras i Candi o P. Bosch Gimpera, i la reproducció de textos antics en català i d'interés històric de la mà de Frederic Pastor i Lluís, director del Museu-Arxiu Municipal de Tortosa.

Alllarg de l'existència del rotatiu en aquesta primera etapa, s'hi destacaren determinats esdeveniments i homenatges, com el tribut pòstum al col laborador Sr. Josep Vérgez i Peira. D’altra banda, en el núm. 82 es féu referència als Jocs Florals de 1920, organitzats per la Lliga Espiritual de la Mare de Déu de la Cinta, que se celebraren a Tortosa en substitució del certament literari previst inicialment -al qual feia referència Francesc Mestre i Noé en el núm. 79 de la revista, i on es reproduïa el poema «A la Verge dels Àngels» de Josep Albert i Navarro, premiat amb la Flor Natural dels JF de 1920. Finalment, cal citar la llista de «Refrans y modismes» en tortosí que F. Pastor i Lluís publicava en el núm. 97-98, d'agost de 1921.

Pel que fa a l'abast temàtic dels textos escrits en català durant aquesta primera etapa de La Zuda, s'ha d'assenyalar el caràcter local del seu contingut: els que parlen de la història i els costums de Tortosa, especialment en el cas del cronista Francesc Mestre i Noé i de Ramon Vergés Pauli; de personatges il lustres tortosins; dels artistes locals -sobretot Mestre i Noé-; les col laboracions poètiques de literats $i$ aficionats tortosins, $i$ algun altre text d'abast comarcà com els que es refereixen al ferrocarril del Val de Zafán de Joan Torner i Balaguer.

Joan Torner i Balaguer, en acomiadar-se del càrrec de secretari de l'Ateneu al gener de 1924, s'identifica com a «tortosí comarcà» i explicava que l'obra de l'Ateneu havia estat sempre «d'un tortosinisme generós i ample, en consonància amb les realitats geogràfica i històrica; no un tortosinisme estret de mires i localista».

Que si tortosins som tots els que habitem des de la Roca Follatera a la mar, i des del Coll de Balaguer al riu Cenia, forçós es que'ns trobessem perque es una mateixa la nostra autóctona cultura, i un mateix el problema de tots. Per això, jo, tortosí comarcá, si m’acomiado de vosaltres amb un afectuós «a reveure», dic també aixecant el cor i el pensament alhora: DeRTuSA; MÁter NOSTRA; SALVE. (La Zuda 124, gener 1924, p. 7)

Tanmateix, en l'article «Tortosinisme» (núm. 134), Torner es queixa del caire que anava prenent el concepte i denuncia que a Tortosa el jovent ja no entenia el tortosinisme en el sentit comarcà sinó en un sentit localista i exclusivista, el qual diferenciava obertament entre els districtes de Tortosa i de Roquetes, tot trencant la unitat de la «comarca tortosina»:

Avui comfesem-ho de pla i rodonament, el tortosinisme no existeix. És a dir, ço que no existeix és el comarcanisme. El tortosinisme que s'ha predicat es aquell tortosinisme estret i carrincló que he blasmat tantes vegades; un tortosinisme tant tortosí, que per ser-ho massa, no poden sentir els altres (...) I la roda del temps, mentrestant, corre depressa anunciant amb claredats de mitjorn problemes imperiosos d'ordre moral uns, materials els mes, que demanen la directriu de la capitalitat. Mes es en va. «Som els de sempre» repeteix l'himne per tota contesta. I la separació 
moral que ha començat a la capital dona el fruit consegüent en els pobles. Trista conclusió que ensenya, que si Tortosa es el cap de la comarca, per ara i tant, està ben lluny encara d'ésser-ne el cor. (La Zuda 134, gener 1924, p. 156-157)

Aquest sentiment localista també es desprén des de les pàgines de La Zuda i de manera progressiva amb el directori primorriverista, especialment a partir del nomenament de Joaquín Bau com a alcalde de Tortosa, i que fa que Joan Torner i Balaguer deixe de publicar-hi amb el seu nom -fins al novembre de 1927-, tot i que continua col laborant-hi amb el pseudònim de Lluís de Montsià. La revista redueix, doncs, la quantitat i la diversitat d'autors que hi publiquen en català. De fet, en la secció «De casa» corresponent al núm. 120, el rotatiu es posicionava a favor de la Dictadura:
El movimiento de renovación, promovido en nuestra patria, aplaudido por cuantos deseaban constamente un cambio radical en el arte de gobernar a la infortunada España por cuanto significa un apartamiento de los viejos cauces por donde se deslizaba la ya vieja politica nacional. Nosotros lo hemos visto con satisfacción, en cuanto es un reactivo enérgico, poderoso contra la inercia de los antiguos gobernantes, contra procedimientos viciados, un saneamiento social y politico y asi creemos que verán todos los buenos españoles la exaltación al poder del Directorio que preside el general Primo de Rivera, que con un gesto lleno de patriótica gallardia, ba tenido la virtualidad de cambiar totalmente la faz de España y de demostrar que no se ha acabado la raza de aquellos caballeros valerosos y justicieros de la Edad Media. (La Zuda 120, setembre 1923, p. 339)

En definitiva, les aportacions en català a $L a Z u d a$, es reduïren a poc a poc fins a quedar-se amb: Ramon Vergés Pauli, especialment amb les seccions «Espurnes de la llar» i «Fulles de la història de la Santa Cinta»; Francesc Mestre i Noé, amb la secció «Artistes tortosins» 1 «Contalles crepusculars tortosines» (1925-1927); i Manuel Beguer Piñol, amb la secció «Llinatges tortosins». A banda d'aquestes tres autors, cal esmentar, sobretot, les aportacions poètiques de Lluís de Montsià, Mn. Tomàs Bellpuig i Maria Fonts, que inaugura la secció «Nostres poetesses» entre 1924 i 1928 (núm. 124-148).

\subsection{Segona etapa de la revista}

Malgrat que el director de La Zuda continuava essent Manuel Beguer Piñol, el qual ho era des de 1920, cal parlar d'una obertura de la revista cap a noves aportacions en català a partir de novembre de 1927 (núm. 165), quan comencen a publicar-hi homes que també escrivien a Vida Tortosina, revista bilingüe de nova creació, que es declarava catòlica i d'esquerres, i alguns dels quals s'afilien posteriorment a Acció Catalana; es tractava de Frederic Mayor Domingo, Ferran Segarra, Joan Torner i Balaguer, Josep Via, Carles Sánchez Pastor... i els poetes Mn. Joan Abarcat i Joan Povill i Adserà, entre altres. Així, doncs, s'incorporen a $L a Z u d a$ nous col laboradors que no compartien un criteri lingüístic tortosinista sinó que empraven un model de llengua fabrià. Aquest canvi d'actitud en la revista fou degut, sobretot, a la nova presidència de l'Ateneu a càrrec del mestre nacional Fermí Viladrich, el qual va aconseguir que l'Ateneu actués com un veritable centre cultural, i a un canvi ideològic en la revista -i no a Manuel Beguer Piñol, com apunta Subirats (2009: 29). La reaparició de Joan Torner i Balaguer com a col laborador fou un altre dels símptomes del canvi experimentat pel rotatiu. 
L'entitat es dividia en les seccions de: Belles Arts, que s'encarregava d'organitzar exposicions, conferències, concursos, etc.; Recreativa, novament constituïda a partir de 1928, des d'on s'organitzaven balls, tes i concerts per als dies festius, i Excursionista. Posteriorment naixien les d'Economia i Ciències Socials, Esportiva, amb celebracions com la Festa del Pedal (Vida T. 204, 25-VII-1931, p. 13), i d'Agricultura, des d'on s'organitzà la Setmana Agrícola, entre el 14 i el 20 de desembre de 1930 (Vida T. 175, 3-I-1931, pp. 3-5). En relació amb les conferències, ocuparen la tribuna de l'Ateneu destacats homes de la cultura d'arreu dels PPCC. Així, per exemple: Joan Puig i Ferreter (Vida T. 40, 17-v-1928); Joan Povill Adserà (Vida T. 85, 4-IV-1929); Pompeu Fabra, sobre «La mal anomenada per alguns llengua tortosina» (Vida T. 204, 25-VII-1931); o l'historiador Antoni Rovira i Virgili, el qual tractava el tema de «La Constitució catalana i els problemes territorials» (Vida T. 289, 11-III-1933, p. 17-18). S'hi dugueren a terme diverses sessions literàries com la del poeta Manuel Vilà i Dalmau, tot presentant a l'auditori el seu llibre de poemes Quan l'amor dictava, precedit d'un pròleg d'Apel les Mestres (Vida T. 83, 21-III-1929, pp. 15-16). I s'hi organitzaren concursos, com el de vestits de pagesa tortosina antiga o el concurs fotogràfic per les Festes de la Cinta (Vida T. 150, 12-VII-1930, pp. 15-16).

Una altra novetat fou la col laboració d'El Llamp (Terra Alta) amb La Zuda; del jove poeta gandesà Joan Povill Adserà, el qual havia rebut la Flor Natural en els Jocs Florals del Rosselló amb la composició «Llorer vermell», i també del poeta Joan Abarcat, qui aportava diversos articles al rotatiu..

D'altra banda, hi tornen a haver aportacions foranes com la del folklorista català Valeri Serra i Boldú -autor de Llibre del Roser a Catalunya- amb «Captiris i cançons de pandero» (núm. 172 i 173); la de l'historiador Francesc Carreras Candi o de la poetessa Josefa Rosich Cotuli (núm. 153-181).

El jove tortosí Carles Sánchez Pastor inicia la seua col laboració a la revista l'any 1928 amb el poema «Tarda morent» (núm. 176) i, posteriorment, hi escriu articles de l'estil dels de Vida Tortosina, com: «Per què no hem celebrat ací la diada del llibre?» (núm. 177); «El camí del triomf» (núm. 183); «Literatura 1929» (núm. 187); «Política i literatura» (núm. 196-197), i «Un triomfador. Sebastià Juan Arbó» -on parla de l'èxit de la novel la L'inútil combat- (núm. 208). J. Cachot i Lluís, que ja havia escrit diversos articles en castellà des del núm. 165, comença a col laborar-hi en català en els números 191 i 192, amb «Llengua catalana» $\mathrm{i}$ «Llengua catalana II», corresponents als mesos de maig i juny de 1930.

Pel que fa a les col laboracions poètiques d'aquesta segona etapa, al marge de les de Tomàs Bellpuig o Lluís de Montsià, cal citar: Joan Povill Adserà, Josefa Rosich Cotuli ( $†$ ), Maria Fonts, Carles Sánchez Pastor, Ramon Vergés Pauli i Isabel Rodés de Cardoner, entre altres.

Durant els mesos de febrer i març de 1931, sota la direcció de Suárez de Figueroa, la revista -ara bimestral- manifestava que no volien apartar-se del seu ideari: «el seu amor a Tortosa i a l'apostolat cultural» que s'havien imposat des dels inicis de la publicació, divuit anys enrere. Tot i

SCRIPTA, Revista internacional de literatura i cultura medieval i moderna, núm. 7 / juny 2016 / pp. 80 - 101 ISSN: 2340-4841 · doi:10.7203/SCRIPTA.7.8443 
el seu desinterés pel vessant polític, en l'editorial «Del momento» (núm. 201-202), es fan ressò de la reforma de l'Estat i de la nova forma de govern, la República, amb la qual s'oferien a cooperar, i de l'imminent reconeixement de la personalitat de Catalunya. I de la mateixa manera, feien palés el desig que, amb la desaparició de les diputacions i la major fisonomia de les comarques, s'hi respectés també la personalitat de la comarca tortosina. Malgrat això, en l'editorial corresponent al núm. 209-210, gener-febrer de 1932, es diu que hom s'havia oblidat d'aquesta comarca en la nova Divisió Territorial de Catalunya, que ara s'anomenava Baix Ebre i que, per tant, es deixaven al marge les partides de Roquetes i Gandesa (es referien als antics districtes electorals de Roquetes i Gandesa), que antigament formaven part de la Castellania d'Amposta i que, segons La Zuda, haurien de formar part de la comarca «per afinitat de caràcter, de llengua, de costums i d'interessos».

Finalment, en una entrevista realitzada per Vida Tortosina al president de l'entitat, el Sr. Cardoner explicava que l'Ateneu pretenia ampliar el seu abast cultural i, a més de les conferències que s'hi anaven donant, volien introduir-hi cursets de llengua i literatura catalana, geografia, comptabilitat, música i fins i tot celebrar uns Jocs Florals (Vida T. 289, 11-III-1933, pp. 8-9). Tot i que a Vida Tortosina es parla de la reaparició de La Zuda, la qual seria editada trimestralment i redactada majoritàriament en català (Vida T. 301, 3-VI-1933, p. 18), la realitat és que La Zuda desapareixia definitivament durant el mes de juliol de 1933.

\subsection{Col laboradors habituals de La Zuda}

Ramon Vergés Pauli inaugura la secció «Fulles de la Historia de la Santa Cinta» amb l’article «Lo miracle de la bomba» (núm. 119). Al gener de 1927, hi reapareix la secció «Espurnes de la llar» amb «Contalles o narracions casolanes fetes amb pressa i sense traçar-hi cap pla previ», com ell mateix diu, amb aportacions com «Vida tortosina. Lo famós Club Recreatiu. Los González en la intimitat. Contalles i anèdotes».

Mn. Tomàs Bellpuig inicià la seua aportació a $L a$ Zuda en la secció «Musicales, corresponent al núm. 88 (octubre de 1920). Posteriorment, col labora en la secció «Nuestros poetas»/ «Nostres poetes» a partir del núm. 116, on trobem «L'apòstol de la joventut». Entre els números 130-131 i el 137, de setembre de 1924 a febrer de 1925, hi publica el drama Soldat de Crist per escenes. Al gener de 1926, «Himne per a un Orfeó Tortosí̀ (núm. 146) i l’any 1931 s’hi reprodueix un fragment de la novel la Or a les brases²

\footnotetext{
2 A més de L'art d'escriure bé, una adaptació de les Normes Ortogràfiques l'IEC al parlar tortosí i del qual es van publicar quatre edicions (1913, 1922, 1930 i 1934), també escrigué drames com: Sang tortosina, Màrtir d'Eucaristia i Soldats de Crist, i el drama sacre musical, en un acte i en vers, de La Virginitat triomfant (1935). Entre altres obres religioses, el 1933 publicava la novel la ascètica Or a les brases, en el pròleg de la qual fa evident la preocupació per la unitat de la llengua catalana. També es va dedicar a la traducció i, en col laboració amb Josep Vergés, va publicar una traducció de l'epistolari de Sant Cebrià a la Fundació Bernat Metge. La seua obra poètica es decanta per la poesia religiosa, sobretot de tema eucarístic, amb clares influències de Verdaguer i de Costa i Llobera (Aragonés, 2008: 14) i és l’autor de Composicions Eucarístiques (1922-1926), que va tenir molt bona acollida entre els literats de l'època, i que va portar Enric Bayerri a considerar-lo «poeta tortosí de l’ideal» i Mn. Manyà com a «poeta de l'Eucaristia de la nostra literatura» (Subirats, 2009: 36). A més, escriví la lletra de diversos goigs, que promovien la devoció popular, i de novenes.
} 
(núm. 201-202). Altres aportacions en prosa són: «Don Josep Vergés» (núm. 159) i «Un català fill d’Orense» (núm. 175), en relació amb el bisbe Manuel Ros de Medrano.

El rapitenc Lluís de Montsià (Joan Torner i Balaguer) s'inicia a La Zuda com a traductor, el 1919, en la secció anomenada «Literatura francesa» (núm. 77) i, a partir de 1927, en la secció «Literatura anglesa» (núm. 162); posteriorment, s'encarrega de la secció «Literatura italiana» en els núm. 105, 125, 137, 139, 143 i de la secció «Literatura portuguesa», núm. 130-131.

Com a poeta, inaugura la secció «Página literaria», amb la composició poètica titulada «A...» (núm. 82). Altres composicions són: «Canta, canta mariner...» (núm. 191); «Sant Jordi» (núm. 201-202); «La bandera dels Alfacs» (núm. 208), etc.

Com a articulista signa com a Lluís de Montsià en «Després d'uns Jocs Florals» (núm. 84), en què defensa la idea d'una «escola tortosina» dins la literatura catalana i manifesta la conveniència de celebrar a Tortosa més certàmens literaris com el dels JF de 1920, a fi de dignificar i enlairar la variant tortosina de la llengua catalana. Altres articles d'interés comarcà són: «La sortida al mar. El port dels Alfacs» (núm. 94); «Pro carril Val de Zafán. Tornant de Gandesa» (núm. 97-98); «Del carril del Val de Zafán» (núm. 100). I signa com a Joan Torner i Balaguer en els articles: «El carril de Val de Zafán, ideal d'un país i ideal d'un poble» (núm. 103).

El poeta Joan Abarcat inicia la seua col laboració en La Zuda amb l'article «Records vells i noves realitats» (núm. 171) i «Qui t’ha vist i qui et veu, ciutat de Maria» (núm. 174), arran de la visita a Tortosa que féu per la celebració de la Baixada de la Cinta. En «Bellíssimes coincidències» (núm. 184), explica les Festes de la Cinta de l'any 1918 i en «Tortosins que van a Tortosa» (núm. 194), parla de l'experiència pròpia en tornar a la ciutat on es formà com a capellà.

Manuel Beguer Piñol no comença la seua aportació en català a la revista fins al mes de març de 1926 (núm. 148). En aquest número inaugura l'única secció en què hi escriu: «Llinatges tortosins».

En aquesta secció es proposa de «fer reviure» les primeres nissagues de l'antic terme i vegueria de Tortosa de què es té constància, i desenvolupa la genealogia i també l'heràldica relacionada amb aquests llinatges. Beguer Piñol s'adreça al lector tot objectant que «si ets amant de Tortosa, llegirás en gust estes ratlles» (núm. 148). En el segon dels seus articles (núm. 149), al ludeix al sentir comarcà del tortosinisme, que coincidia amb Joan Torner i Balaguer: «Al ser tots germans los de la vall de l'Ebre, des de la Roca Folletera fins al mar, constituim una sola i única gran família». Malgrat això, des de les planes de la revista es percep un fort localisme durant el directori primorriverista, al qual es mostra afí. Així, aprofita l'avinentesa per a tributar un elogi a l'Ajuntament de la ciutat i al seu alcalde, «presidit per lo jove i entussiasta alcalde nostre molt estimat don Joaquim Bau» (La Zuda 149, abril 1926, p. 66). I com a reflex d'aquest tortosinisme, s'acomiada del lector amb el lema: Ave Dertusa, Mater nostra, Salvem!, que també havia estat emprat per Joan Torner i Balaguer, com ja s'ha dit. Tanmateix, Manuel Beguer Piñol no comparteix l'actitud lingüística amb 
Joan Torner i Balaguer, el qual esdevé un dels impulsors del model lingüístic fabrià, mentre que Beguer esdevé un dels màxims representants del model tortosinista dels anys 30.

El polígraf tortosí Francesc Mestre i Noé emprén la seua fidel col laboració al núm. 30 de La Zuda, amb l'article «Moviment del port de Tortosa en 1865. Matriculats i terrestres», a partir del qual s'observa el procés de canvi «particular» que Mestre realitza cap al model de llengua tortosinista. La temàtica dels articles de Mestre i Noé anteriors a les «Contalles crepusculars tortosines» se centren a parlar dels aspectes culturals que per a ell més caracteritzen la ciutat, com són: els artistes clàssics tortosins -pintors i escultors i les obres; els personatges il lustres coetanis a l'autor; els personatges històrics més rellevants que es relacionen amb la història de la ciutat, com el Papa Luna; els tipus populars locals; els oficis dels darrers cinquanta anys a Tortosa i el seu fervor a la Verge de la Cinta. Així, per exemple: «Lo pintor Galwey i la seua Escola» (núm. 43) i «Cinquantenari de la riada i barrancada de 1866» (núm. 44); «Don Marian Galindo i García» (núm. 49); «Renaixement del llenguatge tortosí. Don Josep Vérgez i Peira» (núm. 65) i «Don Teodoro González Cabanne. Gran patrici tortosí (1837-1910)» (núm. 66 i 67); «Tapisos teixits i tapisos pintats. La cena, de Tiépolo per A. Cerveto» (núm. 73); «Don Josep Vérgez i Peira ¡Ha mort!» (núm. 74); i «Certamen literari», (núm. 79) -que és una reproducció del cartell anunciador que apareixia en el Bolletí de la Lliga Espiritual de la Mare de Déu de la Cinta corresponent al mes de desembre de 1919, a fi de commemorar l'aniversari del Descens de la Verge de la Cinta a Tortosa, el 25 de març de 1925, i que finalment es convertí en uns Jocs Florals (presidits per Mn. J. Bta. Manyà, essent el secretari del jurat el mateix Mestre i Noé). El 1920 inaugura la secció «Nuestros poetas» amb la composició poètica «L'huracà» (núm. 84); i l'article «iSom fills del riu!» (núm. 85). El 1922 publica: «iAnitorgis!»-conegut traginer de Tortosa- (núm. 103); «Los monuments als mártirs de Tarragona en la Guerra de la Independència» (núm. 104); «De la pintura artística i decorativa. Francesch de A. Lleyxá i Ribera» (núm. 109) i «La perseverancia» (núm. 110-111). El 1923, «L’esclat literari del pintor Lleyxá» (núm. 115); «Mossén Sol. De la castedat, de l'art i de la sabiduria» (núm. 116); «Lo Papa Luna (1423-1923). Lo Cisma» (núm. 123); i inaugura la secció «Artistes tortosins» a la revista, amb l'article «D. Josep Anicet Santigosa i Vestratén. Escultor, metge i pintor (1823-1923)» (núm.120).

Finalment, en el núm. 142 inicia la secció «Contalles crepusculars tortosines», que es correspon amb la seua tasca de cronista oficial de la ciutat, en substitució de Ramon O'Callaghan.

\subsection{1. «Contalles» entre 1925 i 1927}

Francesc Mestre i Noé, es proposa de relatar un seguit de narracions relacionades amb la història de la ciutat, que ell anomena «contalles», sobre «persones i coses representatives d'una desaparició o d'un nou establiment, fill de la necessitat o de la moda» dins l'evolució i el progrés de la ciutat, com diu ell mateix a l'inici del primer relat (núm. 142). Aquest propòsit es duu a terme en les divuit contalles publicades a La Zuda entre 1925 i 1927, en què Mestre transmet allò que li han contat els seus informants, ha llegit dels cronistes anteriors o bé que ell mateix recorda, ja que es refereixen a

SCRIPTA, Revista internacional de literatura i cultura medieval i moderna, núm. 7 / juny 2016 / pp. 80 - 101 ISSN: $2340-4841 \cdot$ doi:10.7203/SCRIPTA.7.8443 
tot el segle xIx, relacionades amb l'antropologia cultural, la prehistòria i la història de Tortosa i que es poden classificar, segons el nucli temàtic, en: personatges, objectes, instruments, urbanisme, llar, aprofitament del riu, cultura i societat, i premsa tortosina.

És destacable l'interés que Mestre i Noé mostra per l'arqueologia -sovint es refereix a la seua col lecció privada de troballes- i per la història de Tortosa. En la major part d'aquestes contalles, es remunta als orígens d'un procés o d'un objecte per exposar-ne l'evolució històrica fins arribar als segles XIX i xx; per exemple, quan parla del foc, el vidre, la pintura, l'escriptura, etc. Mestre explica la història de la ciutat a través dels elements que per a ell són més representatius del progrés de Tortosa. Un altre aspecte que sobresurt en els seus relats és el profund sentiment tortosinista, la satisfacció de ser fill de Tortosa i l'estima per tot allò que en procedeix. Així, hi destaca els homes il lustres de tots els temps, però també té un record per als personatges més populars, els fabricants $\mathrm{i}$ industrials emprenedors, els artesans, els menestrals, etc.

Mestre i Noé fa ús d'un estil fresc i molt proper al lector, de vegades amb un registre col loquial: «Ara que acabem de pegar una ullada a través de... Seria oportú recordar aquí el nom de...». Sovint diu que «es recorda de» («Ans d'acabar, és de justícia dedicar un record a... Quantes vegades hi penso i quant dolorit ho recordo...»), que ell ha investigat sobre $\mathrm{X}$ tema, que ha visitat tal museu, que ho ha vist en una excursió, etc. És molt habitual de trobar valoracions subjectives i comentaris molt personals sobre un fet o acció. A més, quan ho considera oportú, hi afegeix una explicació o un comentari lingǘstic sobre algun terme com, per exemple, quan parla de l'origen del mot tremps, referint-se al fet de 'traure punta a la ploma d'oca', i que es conservava en alguns pobles de la comarca tortosina (núm. 161); o al terme serra i els seus derivats (núm. 209-210).

\subsection{2. «Contalles» entre 1931 i 1933}

Les set contalles corresponents a aquest període, molt més extenses $i$ aprofundides que en el període anterior, són d'un gran interés històric, arqueològic, antropològic, etnològic i folklòric, i estan molt documentades. Es fa una descripció detallada de certs objectes tot seguint-ne l'evolució des dels inicis prehistòrics a l'època contemporània de l'autor; es descriuen els oficis menestrals duts a terme a Tortosa, com les foneries («La primera fundició de ferro» I, II, III, núm. 199-200, 206-207 i 208) i les serraries («La primera màquina de serrar fusta», núm. 209-210); el progrés de la ciutat concretat en la desaparició d'elements de fortificació de l'arquitectura local («Lo darrer pont de balança», núm. 212), l’aparició de l’enllumenat públic («Los primers quinqués de petroli», núm. 211) i l'enjardinament de l'antic fossar del Rastre («Los jardins públics del Rastre», núm. 217). Finalment, Mestre dedica una contalla als primers arrossaires del delta de l'Ebre i a l'establiment definitiu del cultiu a les nostres terres («Lo cultiu de l'arròs i’l primer molí de despellarofar-lo», núm. 216). 


\section{Germanor}

Germanor és un butlletí cultural i literari, bilingüe, que sorgia a finals del mes de juny de 1918 per iniciativa de l'Associació d'antics alumnes del Col legi Sant Pere de l'Orde de la Salle de Tortosa. Es tracta d'una publicació bimestral, amb articles escrits sobretot en castellà, però també en català i, en menor quantitat, en francés. La revista es repartia gratuïtament entre els socis, que el 1925 formaven un total de 180 (núm. 29) i, per tant, d'un abast lector molt reduit. Un total de 57 números constitueixen el rotatiu, el darrer dels quals correspon al juliol de 1936.

El butlletí, doncs, visqué de ple tot el període de la dictadura primorriverista, en una ciutat comandada pels homes d'Unión Patriótica i amb el protagonisme destacat del carlista Joaquín Bau Nolla. Bau va acabar esdevenint un home clau de l'anticatalanisme a la ciutat, la qual cosa afavoria el caire espanyolitzat creixent de la Tortosa de la segona dècada, juntament amb el beneplàcit del bisbat tortosí, i d'una manera especial amb l'arribada de Félix Bilbao. El mateix Bau recorda en el primer de dos articles publicats a Germanor amb el títol «Remembrances» (núm. 1), com va nàixer l'Associació -de la qual era membre- a partir d'una primera trobada d'antics alumnes que desitjaven realitzar un tribut d'homenatge a un dels germans de les Escoles Cristianes, que havia estat professor i director del Col legi Sant Pere, el Germà Roc.

Manuel Beguer Piñol fou el director de la revista Germanor, com també ho fou de La Zuda des de 1920 -com s'ha dit- i president de l'Associació fins a 1925. Aquesta és la salutació a la premsa de Beguer (núm. 1): «A la premsa tortosina, en especial, li demanem mos considere com a nou i benvolgut confrare, i'ls saludem convensuts de que sabran veure en natros a una joventut que desitja puguer demostrar lo fogós entussiame que hi viu en tots los cors dels qu'hem sigut educats pels fills de La Salle».

Germanor conté el subtítol Publicació oficial de l'Associació d'Antics alumnes del Col legi de Sant Pere Apòstol de Tortosa, fins que és traduït al castellà a partir del núm. 29, corresponent a l'octubre de 1926, quan esdevé la llengua de redacció gairebé de manera exclusiva. L'única secció que es manté escrita en català a partir del número esmentat és «Carnet de Notes», formada per gasetilles referides a naixements, casaments, defuncions, etc. Aquest canvi d'actitud en la revista es degué, probablement, a la pressió exercida per l'alcaldia i la mitra tortosina sobre el rotatiu.

Pel que fa al criteri lingǘstic en català, la redacció del rotatiu i la major part dels col laboradors comparteixen una mateixa ideologia: el tortosinisme. A Germanor escriuen en català: Manuel Beguer Piñol, Francesc Mestre i Noé, Maset, Ramon Vergés Pauli, F. Tallada Cachot, Tomàs Bellpuig -només amb el poema «Cant de la joventut» (núm.16)-, Joaquín Bau, Glauco, Roch, Germà X[...] i F. de Efe, entre altres; mentre que hi ha algunes col laboracions esporàdiques $\mathrm{i}$ individuals redactades en català normatiu i de procedència oriental, com les del Dr. R. Trinquet, J.M. Queralt i Rosell, David Star, Gironí i Business. I pel que fa a les seccions escrites en català cal assenyalar: «Borsa de Treball», «Cultura» $\mathrm{i}$ «Carnet de Notes». 


\subsection{Temàtiques}

Quant a l'abast temàtic dels textos de la revista escrits en català, Germanor no es limita a tractar qüestions pertanyents a l'àmbit religiós, que és predominant (com el record al germà Roc, el fervor a la Verge de la Cinta i a la Immaculada Concepció, l'admiració pel fundador de l'orde, les virtuts de l'Associació, l'anunci de diferents trobades d'exalumnes i les celebracions dels aniversaris del rotatiu, les festivitats religioses, etc.) sinó que es tracten altres temes, sempre relacionades amb Tortosa, com: el renaixement literari tortosí; els primers Jocs Florals a Tortosa; els pintors tortosins contemporanis; l'anunci de la imminent publicació de les Composicions encarístiques de Tomàs Bellpuig (1922), al qual anomenen «el Verdaguer tortosí», amb un pròleg de Mn. Manyà; o altres aspectes de caràcter antropològic i cultural com en «Quadros tortosins», de Manuel Beguer Piñol; i, finalment, la necrologia.

En relació amb les notícies de l'àmbit religiós, Manuel Beguer Piñol, com a veu representativa de Germanor, manifestava una profunda admiració per la patrona de Tortosa i demana de fer una exposició iconogràfica de la Verge de la Cinta per les festes majors de 1918 (núm. 2), amb les obres que hi havia disperses per la Catedral, el Museu, esglésies, sagristies i arxius de cases antigues, $i$ altres de cedides per propietaris particulars - proposta també recollida en el Bolletí de la Lliga Espiritual de la Mare de Déu de la Cinta-. A més, es referia a la col lecció històrica de la Baixada de la Cinta d'Antoni Cerveto i del seu germà Ricard amb la «Perla de l'Ebre», que és com Beguer anomenava la ciutat de Tortosa.

D’altra banda, en la secció «Carnet de Notes» corresponent al núm. 34 (abril de 1928), s’anunciava la celebració del xv cinquantenari del Descens de la Verge de la Cinta a la ciutat per a fer-la dipositària de la cinta sagrada, arran de la qual sorgia la publicació de La Santa Cinta. I en el núm. 36, s'explana que La Santa Cinta es preparava per a celebrar la commemoració dels 25 anys de la fundació del Col legi Sant Pere Apòstol de Tortosa, emplaçat aleshores a la Plaça Alfons XII. Les festes s'havien de celebrar durant el mes de maig de 1929, tot i que el col legi havia estat inaugurat al setembre de 1904, perquè no coincidissen amb les festes de la Cinta.

Pel que fa a l'Associació, Glauco, en «Llaçades d'Unió» (núm. 12), parlava de les dues virtuts dels seus membres: «caritat» $\mathrm{i}$ «germanor». I és precisament la «caritat heroica» allò que s’hi destaca de l'alcalde Joaquín Bau, arran de la seua gestió en la catàstrofe ferroviària produïda a Tortosa l'1 de setembre de 1925, per la qual li havia estat sol licitada la creu de Beneficència. I la revista La Zuda li rendeix un tribut d'afecte i d'admiració, al qual s'adhereixen des de Germanor: «Rébigue tan sols una abrassada de Germanor, pos sap ben be quan se'l vol en esta casa» (Germanor 29, octubre 1926, p. 10). I en la pàgina 15 del mateix número, se'l felicita pel seu nomenament com a Corredor Reial de Comerç de Tortosa. Així, doncs, és evident la bona entesa entre la revista i l’alcalde de la ciutat tot i que la aquesta es mantenia manifestament al marge de la política.

SCRIPTA, Revista internacional de literatura i cultura medieval i moderna, núm. 7 / juny 2016 / pp. 80 - 101 ISSN: 2340-4841 · doi:10.7203/SCRIPTA.7.8443 
Amb la instauració la II República, no s'observa cap canvi en relació amb el contingut del rotatiu, i només en la secció «Carnet de notes» del núm. 42, hom parla de la data històrica del 14 d'abril de 1931: «Reconeguda ja per casi tots los Estats, natros, seguint les normes de la Santa Iglesia, no sols l'acatem, sinó que mos posem al seu costat per a treballar pel bé d'Espanya, i molt especialment de Catalunya i Tortosa, defensant los principis d'ordre, familia, propietat i religió, essencials per a que la pau sigue sincera, ferma i duradera» (Germanor 42, abril 1931, p. 12). Tot i no voler fer valoracions polítiques, en el mateix número es publica un article que advertia els pares i les mares, mestres i professors del «perill» de l'Escola Única que consideraven un atac de la República a les escoles i als mestres catòlics, oficials i privats. Hom afirma que es pretenia privar els pares de la llibertat legítima d'elegir els professors que havien d'educar els fills.

La Escuela Única significa, por lo tanto, el cierre de todas las escuelas católicas; lo que equivaldría en España
a la supresión de las Escuelas privadas, que actualment educan más de un millón de niños, y a la supresión
del Catecismo y del Crucifijo en todas las escuelas del Estado, porque la Escuela Única no es más que un
ataque encubierto a la conciencia de los maestros católicos, a quienes se trata de imponer una pedagogía sin
Dios, aunque no se declare asípor ahora. Sea como fuere, la Escuela Única es un atropello brutal del padre
de familia por el Estado, que les arrebata los hijos, los clasifica e intenta imponerles violentamente la profesión,
no obstante ser los padres quienes deben disponer a su voluntad de la educación de sus hijos. (Germanor 42 ,
abril 1931, p. 6)

\subsection{Tortosinisme}

A través de les planes de la revista s'observa un fort sentiment tortosinista com a ideologia, com declara Manuel Beguer Piñol en nom del rotatiu en «Notes d'Art» (núm. 5). Aquest tortosinisme és localista i no comarcà -malgrat els esforços de Beguer i de Torner des de La Zuda-, ple de fervor a Tortosa i a la Verge de la Cinta, i s'hi destaca el «particularisme tortosí» davant la resta de ciutats de Catalunya. El col laborador Maset, que enceta una secció amb el títol «Cartes bimestrals» (Germanor 5, març 1919, pp. 10), s'adreça a un interlocutor imaginari anomenat Cisquet, a qui diu que: «No sería estrany qu'en eixos díes de patriotisme exaltat te diguessen que ja ha passat a l'historia allò de tortosins, ni catalans ni valencians; no te'ls cregues, seguim sent els mateixos, som encara los de sempre».

En l'article «Lo renaixement literari tortosí»(Germanor 12, juny 1920, pp. 7-8), sense signar, s'argumenta aquest sentiment tortosinista en relació amb la llengua i es diu que hom es degué sorprendre de veure que la revista Germanor no s'escrivia íntegrament en castellà, «acostumats com s'estava aleshores a llegir sempre i en tots llocs la llengua de Castella. Al sorprendres no va diguer caure en lo conte de que sent la revista tortosina i nostra, just i natural era que surtigués escrita en la nostra llengua, que tan sols per ser la nostra, es per a natros la més hermosa». I en el mateix article es destacava la figura del literat tortosí Josep F. Vérgez com el reinstaurador dels Jocs Florals a Tortosa, des de 1861 a 1868, el qual manifestava un entusiasme patriòtic pel renaixement literari de la llengua i al qual es deu -segons es diu en aquest article- el renaixement del «llenguatge tortosí»: 
Tothom sab ja, que'l renaixement del llenguatje tortosí se deu an aquell literat, que de no haverlo reclamat la Mort, hagués sigut un dels més assiduos i valiosos colaboradors de GERMANOR, en quina revista va veure la llum una de ses inspirades poesíes, i en la que haguessem vist més hermosos fruits de sa delicada pluma, pos mos distingia en son apreci i era gran la simpatía que li inspirava nostra obra.

Quant al renaixement literari i musical de Tortosa a partir de 1860, en «Papés vells tortosins» (núm.12) es destaca una altra figura tortosina, la del mestre Enric Camó, el qual es va sumar al moviment regionalista $i$ va instituir una societat coral a la ciutat. Una de les composicions que va despertar més entusiasme fou «Lo Guay Tortosí», escrita pel metge i poeta Àngel Lluís i Rubio, trobada entre papers vells i reproduïda a Germanor per l'historiador F. Pastor i Lluís. La coral del mestre Camó va delectar durant anys el públic tortosí, tot interpretant cançons d'en Clavé i d'autors de la localitat.

En l'article «Pintors tortosins contemporanis», sobresurten cognoms com Pedrell, Querol, Casanovas, Marqués, Baiges, Moisés, Gimeno i els germans Cerveto com a artistes tortosins contemporanis de l'època, dels quals es remarca no només el seu art sinó sobretot el seu tortosinisme:

\footnotetext{
Ells han dut al llenç nostres hortes hermoses, les riberes màgiques de nostre Ebre, nostra gloriosa tradició de la Cinta, nostres costums i nostra historia; ells, pos, mereixen bé de sa patria xica, de lo que diuen patria xica, que és per a natros la gran, la més gran, la més gloriosa. ¡Com que es Tortosa!; la única, la terra de sants i d'artistes (...) quines hermosures són trasladades al llenç, per son inspirat pinzell, fent així, a la vegada, art i pàtria. (Germanor 12, juny 1920, p. 9)
}

Finalment, s'esmentava del certamen literari celebrat a Tortosa per les festes de la Cinta de 1928, en què el segon accèssit al premi d'honor fou obtingut pel germà Saturní-Llorenç, col laborador de Germanor (núm. 36). També es feia referència al diploma honorífic concedit al jove consoci Joan Cid i Mulet, autor de diverses obres teatrals algunes de les quals foren estrenades al Patronat Catòlic de Jesús. A més, es feia constar la felicitació als col laboradors Mn. Eduard Solé i Ramon Vergés Pauli per haver estat llorejats en el mateix certamen, on van concórrer amb composicions de caire històric; i Manuel Beguer Piñol, també premiat pel Compendio de Historia de Tortosa.

\section{La Santa Cinta}

La Santa Cinta és una revista cultural i literària, dirigida per Ramon Vergés Pauli, que sorgia per iniciativa de la Confraria de la Nostra Senyora de la Cinta a fi de promoure la devoció a la patrona de Tortosa i de commemorar el xv cinquantenari del seu descens a la ciutat (1928). La revista, doncs, apareixia a la palestra en l'etapa final del directori de Primo de Rivera. Posteriorment, Tortosa viu la instauració de la II República, sense que s'hi manifestessen diferències de tractament en el rotatiu quant al fet religiós. Tampoc no hi ha referències a la política local ni d'abast general, com també succeïa a Germanor, sinó que els seus col laboradors es limitaren a parlar de la Verge, de la ciutat, dels tortosins i s'hi manté viu l'adagi de principis de segle: Tortosins, ni catalans ni valencians. 
La revista, escrita majoritàriament en castellà i amb algunes col laboracions en català, està composta per un total de 35 números, que es publiquen mensualment durant l'any de la celebració i, posteriorment, fou editada trimestralment o semestral, des del mes de març de 1929 i fins que desapareix, al març de 1936.

També a La Santa Cinta -com a Germanor- la major part dels redactors i dels col laboradors compartien un mateix criteri quant al model de llengua en català, que es reflecteix en els seus escrits, i d'acord amb una mateixa actitud lingüística: la tortosinista. De fet, La Santa Cinta constitueix la màxima expressió de la ideologia tortosinista més localista. El grup d'escriptors, periodistes, etc. que conformà el tortosinisme féu gala d'un fort sentiment catòlic d'admiració, fervor i devoció a la Verge de la Cinta, patrona de la ciutat, i de tot allò que caracteritzava Tortosa i la distingia de la resta de ciutats de parla catalana: és el «particularisme tortosí», especialment rellevant quant a la llengua.

A La Santa Cinta s'observa un major relaxament ortogràfic respecte a Germanor, especialment destacable en Francesc Mestre i Noé i en Joan Moreira, probablement relacionat amb el fet que el rotatiu pertanyés a un àmbit molt concret de lectors, com era el de la Confraria de La Cinta, i que fos publicada a les acaballes de la Dictadura. En general, doncs, s'observa una major descurança i vacil lacions diverses en l'ortografia, a més d'un augment de trets fonètics dialectals, més propis d'un registre col loquial, com assimilacions, dissimilacions, diftongacions, etc. Per tant, cal parlar d'una adopció relaxada de les normes de 1913 pel que fa al codi ortogràfic, sense tenir en compte la reforma de l'Exposició ortogràfica de 1917.

En l'aspecte morfosintàctic, coincideix amb Germanor i amb el sector tortosinista de La Zuda en l'ús sistemàtic de trets propis de la llengua antiga i característics del subdialecte com: el possessiu sena, l'article determinat i el neutre $l o$, el sufix $-i x$ dels verbs incoatius, els adjectius demostratius no reforçats, el present de subjuntiu amb e/a, etc. I allò que crida més l'atenció són les expressions col loquials i les interferències del castellà, especialment quant al lèxic, com es pot veure sobretot en Vergés Pauli i en Joan Moreira.

Tanmateix, cal tenir present que aquest grup de tortosinistes, encapçalat per Francesc Mestre i Noé, Joan Moreira, Ramon Vergés Pauli i Manuel Beguer Piñol, esdevingué un grup minoritari dins el panorama cultural tortosí dels anys trenta, ja que en la major part de les publicacions de l'època, els redactors i els col laboradors dels distints rotatius havien optat per un model de llengua d'acord amb la normativa de l'IEC: La Veu Comarcal, Ara, Acció, Vida Tortosina, i Lluita. I destacà l'actitud de fidelitat a les normes de l'IEC de Tomàs Bellpuig, Joan B. Manyà, Rafel J. Sàlvia, Lluís Climent, F. Tallada Cachot, Rafel Escuder Piñol, Joan B. Ferré Torrelles i la poetessa Maria Fonts Soler en aquest rotatiu.

Pel que fa a les col laboracions poètiques a La Santa Cinta, cal esmentar: Tomàs Bellpuig (Tortosa), Josep Vergés Zaragoza (†), Secundí Sabaté (Tortosa), Gerard Vergés Zaragoza (Tortosa), Ramon Vergés Pauli (Tortosa), Josep Monllaó Panisello (Tortosa), Rafel J. Sàlvia i Lluís Climent (Tortosa), 
a més de Joan Abarcat -que va rebre dues distincions pels poemes «Serà nostra sempre més» $\mathrm{i}$ «Sospirs» al certamen poètic de Tortosa de 1928 (Subirats 2009: 38)- i Rafel Escuder Piñol, que va ser el gran guanyador del certamen poètic de 1928 -amb sis distincions- i dels JF de 1935. I quant a les poetesses: Josefa Rosich Cotulí (Barcelona), Maria Fonts Soler (tortosina d'adopció), Carmen Rochar i Isabel Rodés de Cardoner (Tortosa).

Podem dir que a La Santa Cinta hom troba a faltar noms de pes dins el món catòlic com Lluís de Montsià o Joan de Caro, i col laboradors que hi publiquen molt pocs articles com són Joan B. Manyà i Tomàs Bellpuig, Lluís Climent o Rafel Sàlvia (com també succeïa a Germanor). Probablement això es degué al fet de no estar d'acord amb la ideologia tortosinista -localista i no comarcana- que es desprenia d'ambdues publicacions.

\subsection{Els redactors $i$ col taboradors de La Santa Cinta}

Ramon Vergés Pauli, director de La Santa Cinta i arxiver de la Reial Confraria de la Mare de Déu de la Cinta, inicia la seua aportació a la publicació amb la secció «Espurnes de la llan», en què actua com a cronista de la ciutat malgrat no ser-ho oficialment, $i$ on tracta relats de caire històric, etnogràfic i costumista, cròniques periodístiques i monografies, entre altres gèneres. És destacable la proximitat i la connexió que aconsegueix amb el lector com a periodista, el «lector caríssim» com acostuma a anomenar al receptor dels seus relats («I ara es preguntará lo curiós lector...; ja sap lo lector que...»). Vergés Pauli defensa la «font fidel», com són els arxius, a l'hora d'explicar fets històrics i la modèstia li fa dir que ell no arriba a la categoria «d'aprenent d'historiador». Pel que fa a les seues contalles, explica que provenien de les narracions que els avis li havien contat a la vora del foc en nits d'hivern.

Pel que fa a les contalles de Vergés, hi destaquen: la monografia de «Mossén Joaquim Esteve Ortí» (núm. 5), on s'explica que la gent humil que acudia a Tortosa procedent dels pobles del bisbat, com féu Mn. Esteve -nat a la Mola d'Ares del Maestre-, era acollida al Col legi de Sant Josep, dirigit per Mn. Sol: «nostre orgull i nostra glòria més llegítima, les teues parets venerables són un llibre sempre obert aont s'adeprenen llissons d'amor a Tortosa» (Sta. Cinta 5, maig 1928, p. 56). Els «josepets -deia- són el planter dels futurs ministres de Déu», i Vergés i Pauli se’n sentia germà. A «Mudances del temps» (núm. 8), Vergés exposa en què consistia la Publicata de Tortosa, un costum popular de les festes de la Cinta que s'havia perdut a meitat del segle XIx. A «Festes de la Cinta de 1807» (núm. 10) recorda l'afició dels tortosins a les corregudes de bous i descriu les solemnes maitines cantades la vespra de la Cinta en commemoració de la Baixada de la Cinta, i de dues processons en què es passejava la relíquia del Sagrat Cíngol pels carrers de Tortosa. A «Les Cintes dels Portals» (núm. 12), recull una llegenda històrica sobre el siti de Tortosa de 1642. En «Un cas típic de devoció tortosina» (núm. 13), parla de Rosa Cabanne Estrany, mare de Teodor González, com a exemple de dona devota. I en el núm. 14, a «Efemèrides tortosines», relata l'epidèmia del còlera que la ciutat patí el 1885, essent bisbe de Tortosa el Dr. Aznar i Pueyo. En «Un daltabaix en la història tortosina» 
(núm. 20), Vergés explana com es va viure a Tortosa el període revolucionari 1868-1874, amb la descripció de l'episodi de l'epidèmia de la pesta groga. A «Divulgant la devoció de la Mare de Déu de la Cinta» (núm. 26), tracta àmpliament la qüestió de la veneració a la Verge i a la seua relíquia, un cíngol de dotze pams que la Cinta deixà a Tortosa el 25 de març de 1178. Finalment, en la «La capella de la Cinta» (núm. 33), explica que el bisbe Veschi fou l'iniciador de la Capella de la Cinta (1644) durant el seu pontificat, i el capítol de la Catedral acordava de construir-la en una sessió del maig de 1642, poc després de la victòria contra els francesos.

Vergés Pauli és un dels màxims exponents de la ideologia tortosinista més localista i, segons Subirats (2009: 33): «Ha passat a la història com un dels acèrrims defensors del particularisme tortosí. La ideologia del tortosinisme portada als extrems més rancis queda perfectament reflectida en alguns paràgrafs del controvertit article «Tortosins, ni catalans ni valencians» Espurnes de la llar I (1991²: 116).

Joan Abarcat, Manuel Beguer Piñol i Joan B. Ferré dediquen diversos articles a la Verge de la Cinta, en els quals manifesten el seu fervor i admiració per la Mare de Déu. Així, Joan Abarcat escriu les seues col laboracions a La Santa Cinta des de Castellar del Vallés: «iQuin tortosí no l'estima a Santa Cinta!» (núm. 3); «Quadret camperol» (núm. 8); «La mel de l'amor» (núm. 17); «iqué n’és de dolç lo sant recer de la nostra Capella!» (núm. 19); «Animes ferventes vel len i preguen als peus de la Verge» (núm. 20); «iAmunt los cors!» (núm. 28); «La processó de la Cinta de l’any passat» (núm. 29); «Lo rosari de la vespra de la Cinta» (núm. 31); «Missioners de la Verge de la Cinta» (núm. 32); «Estimem-la!» (núm. 33); i «Ja tornem a ser-hi?...» (núm. 34).

El tortosí Manuel Beguer Piñol hi col labora amb: «Fills de la terra tortosina» (núm. 4); «iVeniu, tortosins!» (núm. 14); «La imatge de la Verge de la Cinta de l'escultor Ramon Cerveto» (núm. 18); «Records d'un any sant. L'himne de la Cinta al Vaticà» (núm. 26); «Un gran devot de la Cinta. Mossèn Salvadó Rey» (núm. 28); «Un curiós llibre inèdit sobre la Santa Cinta» (núm. 34); i «Un curiós llibre inèdit sobre la Santa Cinta, II» (núm. 35).

Finalment, el tortosí Joan B. Ferré Torrelles enviava els seus textos des d'Ascó, on exercia de curat. Participa en La Santa Cinta el 1936, en concret en els números 31 a 34 amb quatre textos: «Devoció d’Ascó a la Verge de la Cinta», «Miracle?», «Quan será aixó?» i «A reman».

En el cas de Joan Moreira, hi ha un gran relaxament ortogràfic en els seus escrits, amb una proposta ortogràfica que s'allunya del model fabrià i que s'adiu amb el model de llengua emprat per ell anteriorment, per exemple, al Bolletí de la Lliga Espiritual de la Mare de Déu de la Cinta. Hi utilitza algunes solucions de manera exclusiva, com l'ús d'un accent circumflex en mots aguts, i altres que només es conserven en els seus textos com, per exemple, el fet de no escriure cap -r final de manera sistemàtica. Pel que fa a morfosintaxi, Moreira segueix el model de llengua tortosinista, i hi inclou una gran quantitat de castellanismes, especialment lèxics.

SCRIPTA, Revista internacional de literatura i cultura medieval i moderna, núm. 7 / juny 2016 / pp. 80 - 101 ISSN: $2340-4841 \cdot$ doi:10.7203/SCRIPTA.7.8443 
Les aportacions costumistes de Moreira tenen sempre un to amé i irònic, i estan relacionades directament o indirecta amb la Verge de la Cinta i amb el relat d'algun dels seus miracles. Aquestes són: «Fora misèries...jAleluia! » (núm. 8); «Lo gafarronet de Bècu. Record de ma infantesa» (núm. 11); «Benedicite...cantate» (núm. 13); «iiDesperta, ferro!!» (núm. 15); «La tragèdia del cunill» (núm. 16); «Història d’una gota d'aigua» (núm. 17); «D’aquí poc...»(núm. 19); «iTan fàcil que siria!» (núm. 20); «Lo test d’aufàbiga» (núm. 21); «¿De qui és esta pinyora?» (núm. 22); «La venjança del paraigües» (núm. 23); «Esperem les ulleres» (núm. 25); «A través de les ulleres» (núm. 26); «No hi ha mal...» (núm. 28); «Til la i Ave Maries» (núm. 29); «Digues que Paula t’hu diu» (núm. 31); «Mestre Eduardo Torres» (núm. 32); «Il lusió, per ara, només» (núm. 33); «La carrasca i’l borinot» (núm. 34); i «No hu digues que no pot sé...» (núm. 35).

Francesc Mestre i Noé, com a cronista oficial de la ciutat, recorda la commemoració del 7é centenari de la Baixada de la Verge, essent el Dr. Benet Vilamitjana el bisbe de Tortosa, i el certamen literari que s’hi celebrà el 3 de setembre de 1878.

L'autor de Giripigues tortosines (1915) relaciona diverses obres literàries, la temàtica comuna de les quals és la Verge de la Cinta. Així, fa referència a un drama sacre de Josep M. Pauli dedicat al Descens del 25 de març de 1178; un romanç històric escrit en castellà; una novena en vers del tortosí Sinesi Sabater i Lledó; i hi remembra el bicentenari de la publicació d’un poema heroic, escrit en versos llatins i dedicat al Sagrat Cíngol, del franciscà Fra Josep Beltran i Rius. A més, cita diversos artistes relacionats temàticament amb la Verge de la Cinta, com el pintor vinarossenc Josep Dolz i el tortosí Antoni Cerveto -autor d'un distintiu de la Cinta per a la senyera de l'Orfeó Tortosí, tribut encarregat per la Cort d'Honor de la Mare de Déu de la Cinta (La Santa Cinta 28, març 1934, pp. 8-9). Finalment, té un record especial per al jesuita gironí P. Josep Pastoret, traspassat aquell mateix 1936, el qual durant la seua estada a Tortosa dirigí la Congregació de la Verge Maria i Sant Lluís Gonçaga del barri de Jesús, i l'Anunciata del Col legi de Sant Lluís. El Pare Pastoret havia estat premiat als Jocs Florals de Tortosa de 1900 pels seus «Goigs a llaor de la Mare de Déu de la Cinta», composició de caire popular que descrivia la Baixada i les Glòries de la Santa Cinta, publicada a La Veu de Tortosa -on publicà els seus escrits sota diversos pseudònims com Guillem, Camilo Sala i Prudenci, segons Mestre (Sta. Cinta 35, març 1936, p. 3).

\section{Conclusions}

El tortosinisme que es desprén de les pàgines de Germanor i de La Santa Cinta no és un tortosinisme d'abast comarcà, com havia defensat Joan Torner i Balaguer des de La Zuda (1924), sinó un tortosinisme localista, ple d'exaltació i fervor a la Verge i a la ciutat, i que no tenia en compte res del que es pogués donar més enllà del riu Ebre. En totes dues publicacions es mantingué viu l'adagi de principis de segle: Tortosins, ni catalans ni valencians. 
M. Carme Gombau Domingo. Les revistes bilingües a la Tortosa de la II República

Tanmateix, cal tenir present que aquest grup de tortosinistes, encapçalat per Francesc Mestre i Noé, Joan Moreira, Ramon Vergés Pauli i Manuel Beguer Piñol entre altres, esdevingué un grup minoritari dins el panorama cultural tortosí dels anys trenta, ja que en la major part de les publicacions de l'època, els redactors i els col laboradors dels distints rotatius havien optat per un model de llengua d'acord amb la normativa de l'IEC: La Veu Comarcal, Ara, Acció, Vida Tortosina, i Lluita. 


\section{Bibliografia}

Aragonés Salvat, A. (2003): «La llengua catalana dels escriptors tortosins de principis del segle xx» dins de Llengua i literatura a les comarques de la diòcesi de Tortosa, a cura de M. A. Pradilla. Benicarló, Onada Edicions, "Biblioteca La Barcella”, 1, pp. 13-28.

Aragonés Salvat, A. (2003): Refrans i modismes tortosins per Federico Pastori Lluís, publicats en el setmanari regionalista Libertad (1908-1910). http://usuaris.tinet.org/aragones/webrefranspastor/.

Aragonés Salvat, A./ Vidal i Arasa, J. F. (2009): «L’obra musical, folklòrica i literària de Joan Moreira» Recerca, 13. Tortosa, Ed. Arxiu Històric Comarcal de les Terres de l’Ebre, pp. 49-86.

Balcells, A. / Pujol, E. (2008): Història de l'Institut d'Estudis Catalans. Vol. I (1907-1942), Barcelona, Ed. IEC, "Memòries de la Secció Històrico-Arqueològica", LVII.

Bayerri Raga, J. (1996): Teodor Gonzálę i la Tortosa de la Restauració a través de la premsa (1875-1902), Tortosa, Ed. Cooperativa Gràfica Dertosense «Col lecció Dertosa», 44. Sèrie: Narrativa Històrica, 8.

Bayerri Raga, J. (2009): «Teodor González, a la Tortosa de la Restauració» dins d'Ebrencs del segle XIX. Personatges de la història social, política i econòmica del territori ebrenc al segle XIX. Tarragona, Publicacions Universitat Rovira i Virgili, «Sèrie Campus Terres de l’Ebre», 1, pp. 101-114.

Bertomeu i Camós, Ll. (2010): Els inicis republicans a les Terres de l'Ebre 1900-1930, Tarragona, Arola Editors, «Microhistòria», 9.

Buj Alfara, À. (2000): El Vocabulari Català de Tortosa, de Francesc Mestre i Noé. Una anàlisi lexicogräfica, Tortosa, Ed. Cinctorres Club.

Estrampes Blanch, M. / Macià Montejano, C. (2009): «Actituds dels escriptors tortosins de principi del segle xx davant la polèmica sobre les Normes Ortogràfiques». Recerca, núm. 13, Tortosa, Ed. Arxiu Històric Comarcal de les Terres de l’Ebre, pp. 87-125.

Gimeno Betí, Ll. (1994): Estudi lingüistic dels parlars de les comarques del nord de Castelló, Castelló de la Plana, Ed. Societat Castellonenca de Cultura, "Filologia", 1.

—. (1997): Atles lingüístic de la diòcesi de Tortosa, Barcelona, Institut d'Estudis Catalans, «Biblioteca de dialectologia i Sociolingüística», IV [ALDT].

Gombau Domingo, C. (2011): Actes de l'Ajuntament d'Amposta 1936-1939. Aproximació lingüistica i bistòrica. Treball d'investigació dirigit per Lluís Gimeno Betí dins del programa de tercer cicle: 12612 «Interuniversitari en estudis filològics interdisciplinars (Filologia catalana i afins)» del Departament de Filologia i Cultures Europees de la Universitat Jaume I de Castelló de la Plana.

Gombau Domingo, C. (2013): «Aproximació històrica i lingüística a les actes de l'Ajuntament d'Amposta: febrer de 1936/ abril de 1938» dins de Terres de cruilla. Estudis sobre les comarques de la diòcesi de Tortosa. A cura de Tomàs Martínez Romero, Miquel Àngel Pradilla i J. Manuel Quixal. Benicarló, Onada edicions, "Biblioteca La Barcella”, 14, pp. 293-305. 
. (2015): Lapremsa tortosina en català del primer terç del segle XX. Tesi de doctorat dirigida pel Tomàs Martínez Romero i Lluís Gimeno Betí dins del programa de tercer cicle: 12612 «Interuniversitari en estudis filològics interdisciplinars (Filologia catalana i afins)» del Departament de Filologia i Cultures Europees de la Universitat Jaume I de Castelló de la Plana.

Massip i Bonet, M. À. (1989): Aproximació descriptiva al parlar tortosí, Tarragona, Publicacions de la Diputació de Tarragona.

(1991): «Tortosinisme», vol I, cap II, dins El lèxic tortosí: història ipresent. 3 vol. Tesi de doctorat dirigida per Joan Veny i Clar. Universitat de Barcelona. Barcelona, pp. 34-38. http://www.tdx. cat/TDX-0112109-153232/.

Mestre i Noé, F. (1916): El Vocabulari Català de Tortosa, reproducció facsímil de Lluís Mestre (1973), dins de Buj Alfara, A. (2000): El Vocabulari Català de Tortosa, de Francesc Mestre i Noé. Una anàlisi lexicogräfica, ed. Cinctorres Club. Tortosa, pp. 71-109.

- (1984): Contalles crepusculars tortosines. [Recull d'articles publicats a la revista La Zuda entre els anys 1925 i 1933]. A cura de Ramon Miravall, Tortosa, Ed. Dertosa, Coop. Gràfica Dertosense.

Perea, M. P. (2008): Epistolari d'Antoni M. Alcover (1880-1931). Ed. Moll (CD-ROM), Conselleria d'Educació i Cultura del Govern de les Illes Balears.

Perea, M. P. (2013): «Tortosa: entre Gandesa i Vinaròs. Similituds i diferències a començament del segle $\mathrm{xx}$ » dins de Terres de cruilla. Estudis sobre les comarques de la diòcesi de Tortosa. A cura de Tomàs Martínez Romero, Miquel Àngel Pradilla i J. Manuel Quixal. Benicarló, Onada edicions, «Biblioteca La Barcella», 14, pp. 367-397.

Pérez Silvestre, Ò. (2007): «Lletres, llengua i arrelament en l’Església de la diòcesi de Tortosa (18941939)» dins d'Els escriptors castellonencs del primer terç del segle XX i les Normes del 32. A cura de Josep Palomero i Lluís Meseguer. Castelló de la Plana, Acadèmia Valenciana de la Llengua, pp. 123142.

Pitarch Almela, V. (2011): Pompen Fabra, l'autoritat admirada pel valencianisme. Benassal, Publicacions de la Fundació Carles Salvador, 4.

Pradilla, M. À. (ed.) (2003): Llengua i literatura a les comarques de la diòcesi de Tortosa, Benicarló, Onada Edicions, "Biblioteca La Barcella", 1, pp. 13-28.

—. (2014): «Dinàmiques sociopolítiques i procés d'estandarització a les comarques de la diòcesi de Tortosa». Caplletra 57, Revista Internacional de Filologia (Tardor 2014), Institut Interuniversitari de Filologia Valenciana. Publicacions de l’Abadia de Montserrat. pp. 95-127.

Ramos Alfajín, J. R. (1989): La qüestió lingüistica en la premsa de Castelló de la Plana (1834-1938). Castelló, Ed. Servei de Publicacions de la Diputació de Castelló, «Col lecció Universitària, Llengua i Literatura», 3. 
Sànchez Cervelló, J. (2010): «Marcel lí Domingo: un referent en la política ebrenca i catalana» dins d'Ebrencs del segle XX. Personatges de la història social, política i econòmica del territori ebrenc al segle XX. Tarragona, Publicacions Universitat Rovira i Virgili, "Sèrie Campus Terres de l'Ebre", 2, pp. 175-189.

—. (2012): «El republicanisme a les Terres de l'Ebre en temps del CNR». Recerca, 14. Tortosa, Ed. Arxiu Històric Comarcal de les Terres de l'Ebre, pp. 345-398.

Sancho Sancho, Josep (2014): El marcel linisme a les Terres de l'Ebre (1914-1939). Tesi de doctorat dirigida per M. Gemma Rubí i Casals. Dept. d'Història Moderna i Contemporània. Universitat Autònoma de Barcelona. http://www.tdx.cbuc.es/handle/10803/285457. (pdf) [Consultat el 7-i-2015].

Segarra, Mila (1985): Història de l'ortografia catalana. Barcelona, Editorial Empúries, «Les Naus d'Empúries», Timó 1.

subirats i Sebastià, Emigdi (2009): «La Renaixença del català a Tortosa (1878-1938)». Recerca, 13. Tortosa, Ed. Arxiu Històric Comarcal de les Terres de l'Ebre, pp. 11-47.

. (2011a): «Unitat 18: El corrent tortosinista. Joan Moreira» dins de Lletres Ebrenques (21 de desembre de 2011) . http://lletresebrenque.blogspot.com.es/2011/12/.

- (2011b):«Unitat 21: La premsa reivindicativa en català» dins de Lletres Ebrenques (21 de desembre de 2011) http://lletresebrenque.blogspot.com.es/2011/12/unitat-21-la-premsareivindicativa-en.html.

Valls Clua, Jordi (2013): «Història de la premsa de les Terres de l'Ebre (1880-1901)». Recerca, 15. Tortosa, Ed. Arxiu Històric Comarcal de les Terres de l'Ebre, pp. 159-188.

Vergés Pauli, Ramon (1993): Espurnes de la llar. Tortosa, Ed. Dertosa.

Vidal Franquet, Jacobo (2009): «Joan Abril i Guanyabens. La necessitat d'una desmitificació», dins d'Ebrencs del segle XIX. Personatges de la història social, politica i econòmica del territori ebrenc al segle XIX. Tarragona, Publicacions Universitat Rovira i Virgili, «Sèrie Campus Terres de l'Ebre», 1, pp. 4358. 